\title{
Bibliometrics in Information Science: A Citation Analysis of Two Academic Library Journals
}

\section{Mary K. Sellen}

Bibliometrics has been applied in varying degree and format to much of the literature of information science. La Borie ${ }^{1}$ investigated subject, form, and dates of a group of library science dissertations done between 1969 and 1972 . Peritz ${ }^{2}$ analyzed the bibliometric data found in a core of information science journals in numerous articles and her 1977 dissertation. Brace ${ }^{3}$ studied the frequency of citations of specific authors and periodical titles in library and information science dissertations. Windsor ${ }^{4}$ examined the quantity of references in information science papers. It is apparent that there is no lack of interest in this aspect of information science.

Academic librarians, by nature of their situation in higher education, publish more than any other group of librarians. Because of this frequency of publishing, academic librarians rely on journals as a medium for communicating their research efforts. An examination of the references found in journals of academic librarianship can reveal some interesting bibliometric patterns. Questions specifically asked in this study are (1) do academic librarians use more periodical articles or monographs in their research; (2) do articles in specific journal titles reference that specific journal; and (3) in what years are the majority of references found? A citation analysis was conducted in an attempt to answer these questions.

\section{THE STUDY}

References in two academic library journals, College $\mathcal{E}$ Research Libraries and Journal of Academic Librarianship for 1981, were examined. The choice of these two titles was based on a survey done by Swisher and Smith. ${ }^{5}$ CERL and JAL were among the top five journal titles read by academic librarians. By common consensus they are the major journals in academic librarianship. Data tallied included whether the reference was a periodical article or monograph; if periodical article, what specific title; and the date of each reference.

\section{RESULTS}

Thirty-seven articles in CERL were published in 1981 with a total of 454 references. Of these, 178 were monograph citations, 258 were periodical citations and 18 referred to miscellaneous documents, such as unpublished committee reports. The average number of citations per article was 12.27 .

Twenty-seven articles in $J A L$ were published in 1981 with a total of 259 references. Of these, 94 were monograph citations, 141 were periodical citations, and 23 referred to miscellaneous documents. The average number of citations per article was 9.59.

Within the 258 periodical citations in $C E R L$, 65 , or 25.19 percent, were references to articles previously published in CERL; 20 , or 7.75 percent, were references to JAL; 173 , or 67.05 percent, were references to other library and nonlibrary journals.

Within the 141 periodical citations in $J A L, 23$, or 16.3 percent, were references to $C E R L ; 16$, or 11.34 percent, were references to $J A L ; 102$, or 72.34 percent, were references to other library and nonlibrary journals (see table 1 ).

\section{DISCUSSION}

The figures obtained in the results indicate that the articles in both journals use more periodical titles than monographs; however, the number of monographs is surprisingly high. This corresponds to the fact that the dates for both periodicals and 
monographs coincide, indicating that monographs for research are being published in the same years that relevant periodical articles are being published.

$C \mathcal{E} R L$ was the most cited periodical title in itself and in JAL. JAL ranked second in itself and CERL. Other titles that were re- ferred to frequently but not as often as $C E R L$ and $J A L$ were Library Journal and $L i$ brary Quarterly (see table 1). In CERL there is a dramatic drop in citation numbers after the first three titles. The citation numbers decline gradually in $J A L$.

Monographs and periodicals used in

TABLE 1

RANKING OF PERIODICAL TITLES IN THE CITATIONS FOUND IN CERL AND JAL: THE TOP TEN

\begin{tabular}{lclc}
\hline \hline Citle & $\begin{array}{c}\text { Number of } \\
\text { Times Cited }\end{array}$ & Title & JAL \\
\hline CERL & 65 & CERL & $\begin{array}{c}\text { Number of } \\
\text { Times Cited }\end{array}$ \\
JAL & 20 & JAL & 27 \\
Library Journal & 12 & Library Journal & 16 \\
Drexel Library Quarterly & 6 & American Libraries & 11 \\
Library Quarterly & 5 & Library Resources & 9 \\
Reference Services Review & 4 & E Technical Services & \\
Aslib Proceedings & 4 & Library Quarterly & 8 \\
Journal of Documentation & 4 & Online & 7 \\
Library Resources & & Drexel Library Quarterly & 5 \\
\& Technical Services & 4 & Library Trends & 4 \\
Library Trends & 4 & & 2 \\
\hline
\end{tabular}

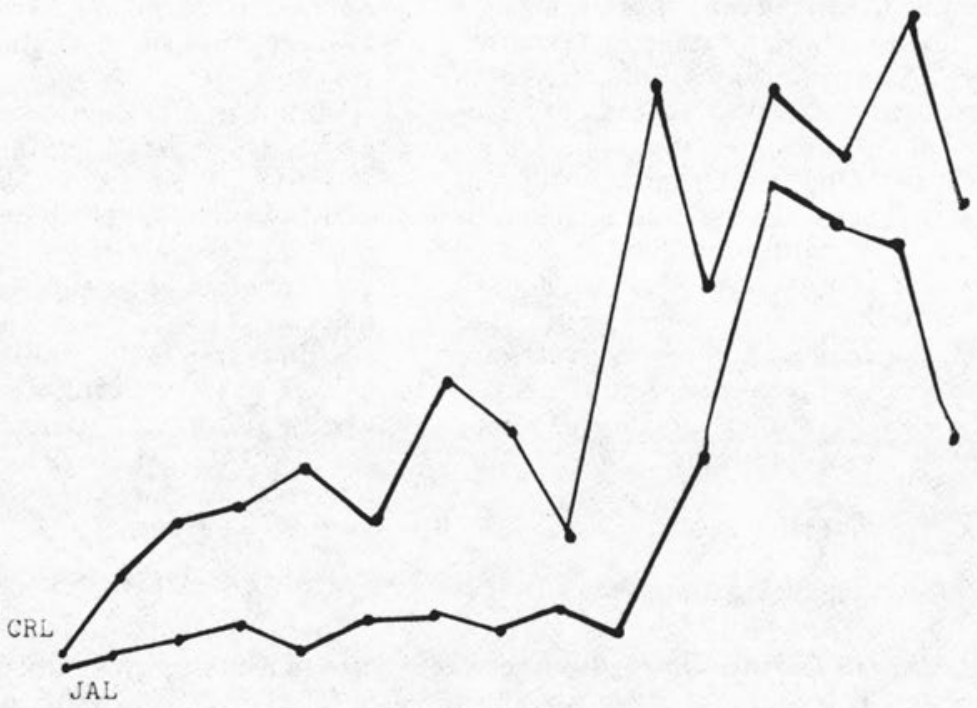

FIGURE 1

Years and Frequency of Citation in Periodicals and Monographs in JAL and CERL 
these 1981 articles were published with the most frequency in the post- 1975 years (see figure 1). Figure 2 indicates that the majority of journal articles in the 1981 CERL were published in 1975, 1976, 1977, 1978 , and 1979 . The years that were the most significant for articles in $J A L$ were 1977, 1978, and 1979. Figure 3 indicates that the most important years for monographs in CERL were 1975, 1976, 1977, 1978, and 1979, which correspond to the journal article years. In JAL, 1977, 1978,

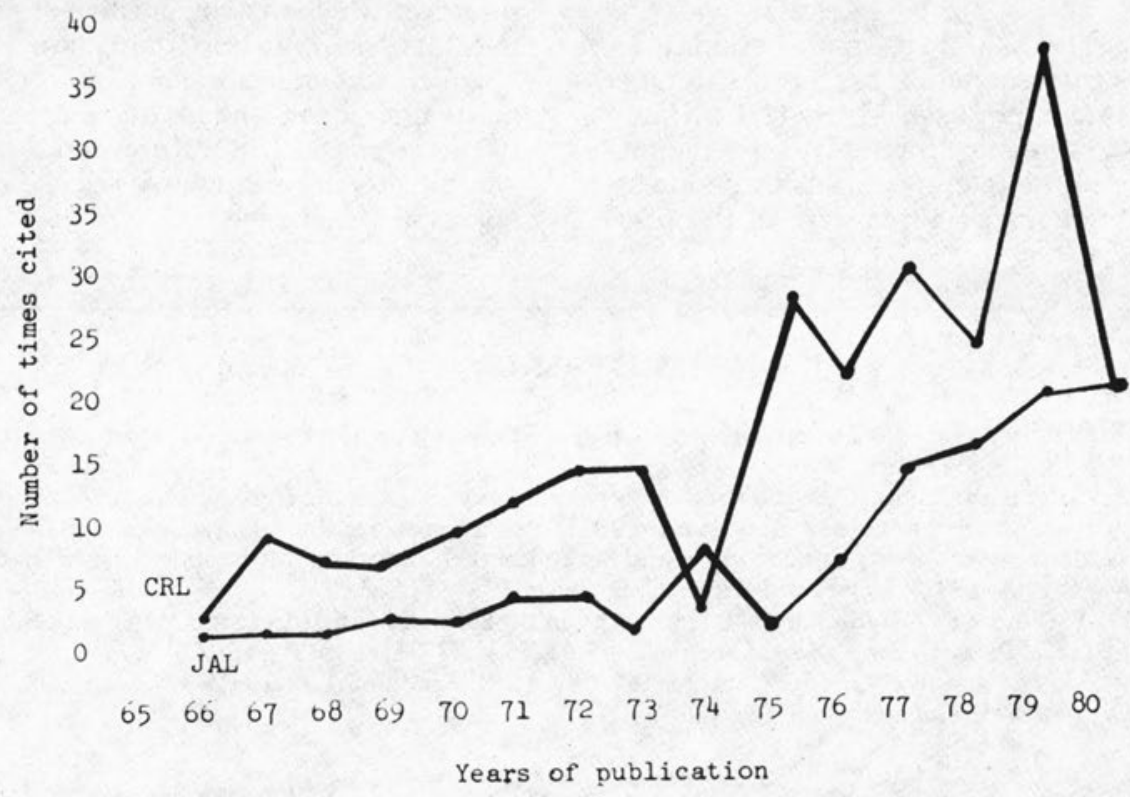

FIGURE 2

Years and Frequency of Citation in Periodicals in JAL and CERL

40

35

30

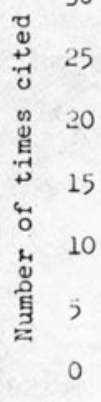

65

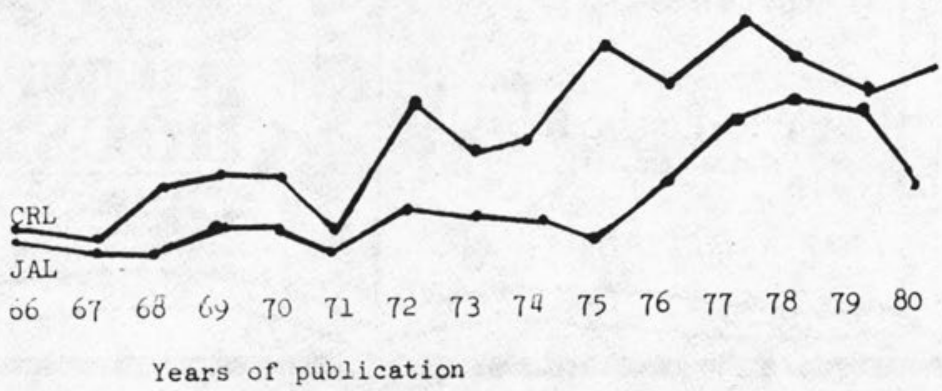

FIGURE 3

Years and Frequency of Citation in Monographs in JAL and CERL 
and 1979, again, similar to the article years, had the most titles published.

\section{SUMMARY}

The questions posed at the beginning of this study can be answered from the citation analyses of articles appearing in CERL and JAL in 1981 as follows: (1) academic librarians do use more periodical articles than monographs, but the number of monographs used is high; (2) CERL and $J A L$ do reference themselves; (3) the majority of the references in both periodical and monograph form were in the post1975 years.
This citation analysis indicates that research in academic librarianship (1) to a large extent reflects the current trends, as the years of publication for references tend to predate the actual research by only three to four years; (2) there is considerably inbreeding within CERL and JAL, the results of which may be positive or negative; (3) CERL is an important journal title in which academic librarians can communicate their ideas; and (4) the time lag between periodical literature and monographic literature in library science does not seem to be large.

\section{REFERENCES}

1. T. La Borie, "Citation Patterns in Library Science Dissertations," Journal of Education for Librarianship 16:271-83 (Spring 1976).

2. B. C. Peritz, "Citation Characteristics in Library Science: Some Further Results from a Bibliometric Survey," Library Research 3:47-65 (Spring 1981). Peritz has also authored other articles in this area.

3. W. Brace, "Frequently Cited Authors and Periodicals in Library and Information Science Dissertations, 1961-1970," Library and Information Sciences 2:16-34 (Apr. 1976).

4. D. A. Windsor, "Citation of the Literature by Information Scientists in Their Own Publications," Journal of the American Society of Information Science 24:377-381 (Sept./Oct. 1973).

5. R. Swisher and P. C. Smith, "Journals Read by ACRL Academic Librarians, 1973 and 1978," College \& Research Libraries 43:51-58 (Jan. 1982).

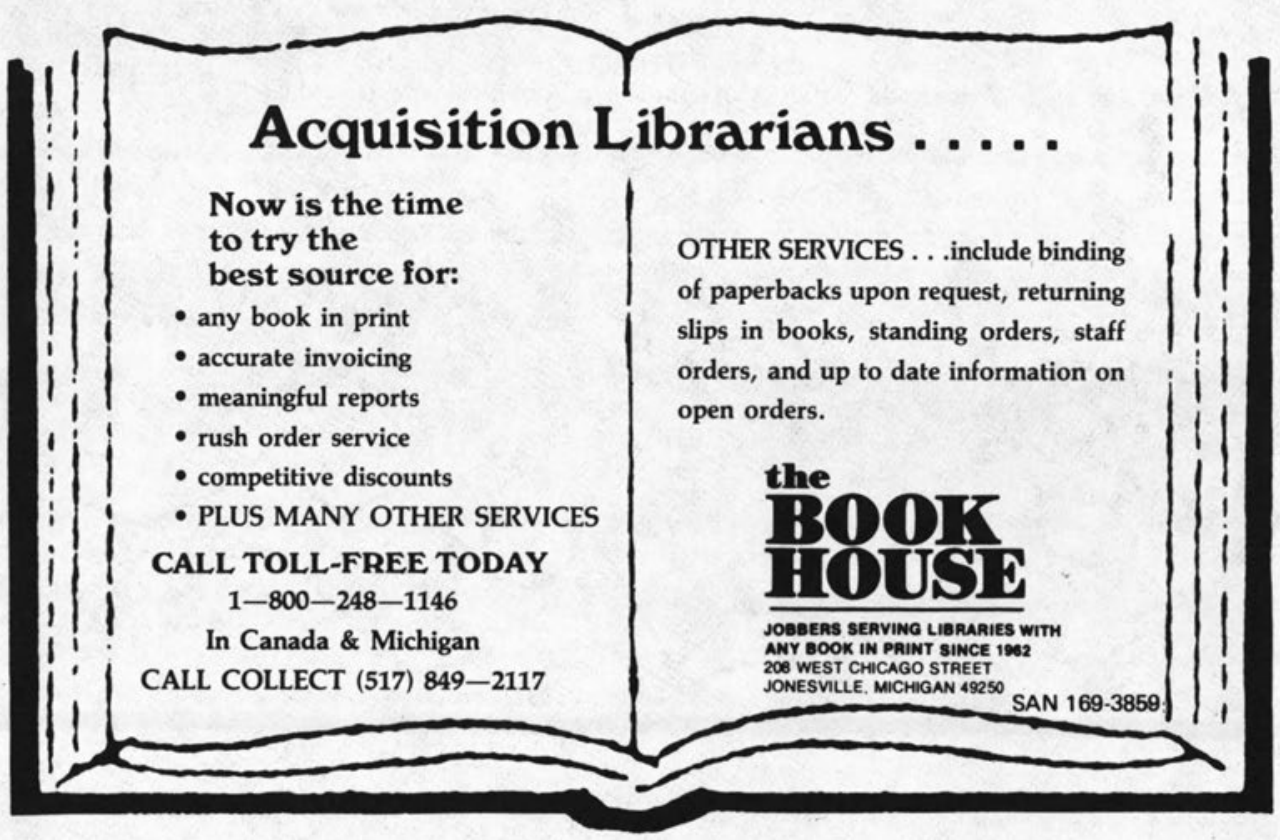

